\title{
The Ideology of Language Purism in Online Interaction of Arabic Speakers
}

\author{
Albatool Ahmad Alhazmi \\ Department of English, College of Language and Translation, Najran University, Saudi Arabia
}

\begin{abstract}
Recently, the critical relationship between ideology and discourse becomes one of the main issues discussed in a wide range of disciplines. Language ideology is described as a dynamic and inconsistent process that must be studied in its given context. This paper aimed to explore the sociolinguistic aspects of language ideology embedded in online interaction of Arabic speakers. The ideology of language purism was the focus of this study. Critical Discourse Analysis was employed as a theoretical framework to analyze the data. The study showed the dynamic nature of discourse and asserted interdiscursive indexing of linguistic purism ideology among Arabic speakers on Twitter. Three key ideological dimensions namely nationalism, modernity and humanity have been recognized from the data corpus. The data asserted considerable influence of people's cultural ideologies related to Islamic and Arabic identities on their language use and attitude. Modernity was also indicated to be one of the central factors influencing speakers' perception about their languages and language use. English was described as a global language to be used to fulfill various integrative, communicative, and affective functions in modern life. Speakers' comments about normality and personality in language use asserted the role those ideological perceptions play in their attitudes towards language purism. The intertextual analysis of the discourse revealed several linguistic features of texts under study including reporting speech, voicing, and shifting. These features served various pragmatic and social functions in this context.
\end{abstract}

Index Terms - language ideology, language purism, critical discourse analysis, textual analysis, indexing

\section{INTRODUCTION}

Language ideology and language attitude have been extensively researched in various areas of applied linguistics. They are among the key factors that should be considered in the study of language use in society (Ag \& Jørgensen, 2013; Hatoss, 2013). The critical relationship between ideology and discourse became one of the main issues discussed in a wide range of disciplines. A question about the way ideology is discursively constructed and embedded in discourse has emerged across social science and humanities studies. Language ideology is described as a dynamic and inconsistent process that must be studied in its given context.

This research was conducted to explore the ideology of language purism embedded in online interaction of Arabic speakers. Specifically, this research aimed to:

- Explore the sociolinguistic aspects of language ideology embedded in online interaction of Arabic-speakers.

- Examine the ways this ideology is constructed in the online discourse.

- Investigate factors that affect language ideology in this context.

Critical Discourse Analysis (CDA henceforth) as a transdisciplinary research approach, has been employed as a theoretical framework for this study. This approach is selected as it allows the dialogue between multiple disciplines and the oscillating theories of ideology.

\section{LITERATURE REVIEW}

Language ideology and attitude have been studied in a wide range of disciplines. Studying language ideology and attitude helps in understanding how everyday interactions reflect and reproduce the social construction of society (Fairclough, 2001, 2003). Language ideology is used as an instrument to describe linguistic practices as it explains how the speakers relate themselves to the languages.

However, in the vast majority of language attitude research, language ideology and attitude have been examined as static entities fixed in the individuals' minds. Thus, statistics-based methods of analysis, such as the matched-guise technique, have often been used to measure language attitude. Although such quantitative methods are useful in language ideology research, more recent scholars, such as González (2003), Jørgensen et al. (2011) and Hatoss (2013), assert the necessity to pay more attention to discourse analysis since language ideology changes over time as it is related to different variables in society, especially political and social conditions. This notion stems from the idea that ideologies are cognitively and socially represented in texts. Hence, discourse analysis is critical for holistic and deeper understanding of language ideology embedded in context.

There are many approaches to discourse-based analysis of language ideology and attitude that involve different levels of analysis. This includes, but is not limited to, Content-based approaches, Turn-internal semantic and pragmatic as well 
as Interactional approaches (Liebscher \& Dailey-O'Cain, 2009). In more recent research, CDA, is widely used in social studies. It incorporates various approaches to analyzing texts including grammatical, semantic as well as conversation analysis (Fairclough, 2003). However, new version of CDA was developed recently by Fairclough (2003) namely 'Transdisciplinary' approach. According to Fairclough (2012, p.452), "Methodologically, this approach entails working in a "transdisciplinary" way through dialogue with other disciplines and theories which are addressing contemporary processes of social change". It draws upon a wide range of approaches to analyzing discourse from both micro textual, and macro sociological levels of analysis.

The ideology of language purism and language separation has been discussed across several linguistic contexts (Jørgensen et al., 2011). These ideologies reflect beliefs and attitudes expressed widely in political and educational discourse over the past decades. Several concepts appeared in literature that describe the person who separates languages and talks only one variety without switching between different linguistic codes (languages or varieties of languages) as an 'idealized native speaker' (Jørgensen et al., 2011). Equally, there are situations in which language is described as 'pure', and 'clean,' while in others it is defined as 'dirty' or 'unorderly' language (Burridge, 2010). Mixing languages is seen as "illegitimate mode of communication" even among the bilinguals themselves (Li, 2000, p.18). Purity refers to forms of languages that involve certain features, while others missing these features are considered as 'impure', 'improper', or even 'incorrect' (Jørgensen et al., 2011). These negative concepts often refer to the varieties beyond standardized form of a language or the forms that are infected by structures associated with other language or even colloquial forms of a language (Ag, \& Jørgensen, 2013). Hence, speakers may violate the purity ideal both by using "foreign" stuff and by using "dirty" stuff (Jørgensen et al., 2011, p.32).

However, on the other hand, positive and more tolerant policy towards language use has emerged. Recently, there are calls from scholars, such as Cummins (2008) and Garcia and Sylvan (2011), for enhancing plurilingual use of languages and encouraging bilingual speakers to utilize their linguistic repertoire especially in academic and business contexts. As language ideology changes over time, there is a constant shift in attitude to the definition of 'proper" language or 'good' use of a language (Burridge, 2010). Thus, the positive attitudes towards specific linguistic behaviors might be found in a society while considered as 'taboo' in others.

Woolard and Schieffelin (1994) mentioned ideologies that had been found in different communities to indicate ideas of better and worse speech. They referred to an ideology of the sanctity of language in an ultraorthodox Jewish community in which the Hebrew language is restricted to be used only in religious sacred discourse. Similarly, standard form of Arabic language is regarded as pure form of Arabic worthy to be studied and used for both written and oral communication (Mizher, \& Al-Abed Al-Haq, 2014). Diglossic condition of Arabic has been discussed widely in literature (see e.g. Ferguson, 2000 \& Palmer, 2007). Standard Arabic is known as a form of high variety for its religious status among Muslims while colloquial dialects are defined as low varieties of Arabic that are usually spoken during daily life conversations. The ideology of the standard language was also discovered in a study of Nugaraite (2017) on people's attitudes toward their regional varieties in Lithuania and migration. In this study speakers were found to be affected by the three main factors, including education, the linguistic pressure from society and the Soviet language policy. People in Lithuania found themselves under pressure to speak right and avoid wrong form of the language while others in migration felt much freer to speak the variety of their choice. Still, according to the standard Lithuanian language ideology, the standard form was regarded for both, people in Lithuania and abroad, as a suitable variety to be spoken through different official events.

Purist ideology also serves several political and economic functions for its people. Certain linguistic varieties or features including some loanwords or accents were identified to be spoken by minorities such as "elite members" in Mexico and Spain to exclude people of the larger economy or political authority (Woolard \& Schieffelin, 1994). Burridge (2010) provides examples of five exchanges which indicate people's relationship and passion to their languages. Several expressions were found in public to imply negative influences of a powerful American English on Australian English such as 'Facing an American Invasion', go on to 'condemn this insidious, but apparently virile, infection from the USA' (Burridge, 2010, p.7).

Hence, language attitudes are highly affected by ideological perspective found in different societies because of various political, cultural, and social factors. Woolard and Schieffelin (1994) explain that language purism is an ideological issue that is greatly affected by standardization process which is complexly related to different issues about language, politics, and power. Thus, researchers (e.g., Woolard \& Schieffelin, 1994; Cummins, 2008; Burridge, 2010; Garcia \& Sylvan, 2011) call for problematizing language ideology and utilizing linguistic diversity rather than assuming or reading its elements.

Furthermore, there is a call for analyzing linguistic features rather than languages as separate entities especially in multilingual environments such as super- diverse societies. According to Jørgensen et al. (2011), the concept of 'languages' as separate and bounded packages also pervades everyday life. They explain that languages are defined socioculturally or ideologically, and so the notion of studying 'language' is not accurate as an analytical level of language practices. The reasons of such claim are provided by Jørgensen et al. (2011, p. 28):

Firstly, this will prevent us from dealing with language production which cannot be ascribed to any individual "language". Secondly, we will inevitably simplify the range of resources employed by speakers. 
For the purpose of this research, the ideology of language purism was examined. More attention was directed to Arabic language valuation among its speakers and their attitudes to switching between Arabic and other languages particularly English. The research is beneficial as it contributes to better understanding of language ideologies from both theoretical and experimental grounds. It sheds light on linguistic ideology related to Arabic among its speakers as expressed in their online discourse. Such clarification is important to recognize the reasons behind ideological behaviors and attitudes towards language use and find ways to deal with such views in different interactional contexts.

Recently, researchers in bilingualism (e.g., Li, 2011; Garcia \& Sylvan, 2011) use several terms such as code mixing (CM), code switching (CS) and translanguaging interchangeably especially when studying sociolinguistic aspects of bilingual behaviors in different contexts. In this study, the terms 'mixing' and 'switching' are used interchangeably to describe the usage of multiple languages by bilingual speakers in one context.

\section{RESEARCH METHODOLOGY}

Critical Discourse Analysis (CDA) as a transdisciplinary research approach, is used as the theoretical framework for this study. This approach allows 'oscillating' between a focus on specific features of texts and other elements related to social structuring of language (Fairclough, 2003). By applying this approach, language ideology of Arabic purism was examined from both textual and sociological perspectives. Hence, this discourse-based analysis leads to a more fruitful examination of the factors affecting language attitudes, as it allows us to explore ideology constructed in discourse. On the macro level of analysis, sociological implications of the texts were included. The social, cultural, and political factors that affect language attitude and ideology were investigated. Linguistic features of the texts (including vocabulary and grammatical structures) were also considered for deeper analysis of texts.

In this research, the data was collected from two online sites: 'The international day of Arabic language' and 'Speak only Arabic' Hashtags in Twitter. Only comments that have explicit references to language and language use valuation were examined. This helped focus on the utterances that reflect language ideology. However, holistic investigation to the interaction in specific context was also important to discover the link between textual, interactional, and social factors.

Data analysis was divided into two main stages: 1) data organizing and coding 2) data description and discussion. After collecting data from the overmentioned virtual sites, they were imported into the NVivo coding program to be organized and coded. This software program is useful especially for qualitative research as it helps to organize and visualize data. It also contributes to analyze quantitative data and discover occurrences of specific features or actions under examination (Feng \& Behar-Horenstein, 2019)

Two methods of analysis were used for this purpose. Firstly, the Grounded Theory approach was used for textuallyoriented analysis of texts. Main themes and concepts related to language ideology of Arabic were identified. Language attitudes towards Arabic and the use of Arabic were explored. Themes were developed inductively from the corpus of data, followed by clarification and thorough explanation. This includes identifying key words and employing textual analysis of posts and comments in several threads that have been selected for the research purpose. A thread is a Twitter series of connected Tweets written by one person.

Secondly, the intertextual analysis of discourse was conducted. It involved an intensive examination of several linguistic features found in the data corpus including reporting speech, voicing, and shifting. According to Fairclough (2003), intertextuality may include different linguistic elements, such as voicing and reporting speech. Fairclough (2003, p.47) explains his view as follows:

We can begin by noting that for any particular text or type of text, there is a set of other texts and a set of voices which are potentially relevant, and potentially incorporated into the text. It may not be possible to identify these sets with great precision, and they may be rather extensive and complex. But it is analytically useful to begin with some rough idea of them, for a significant initial question is: which texts and voices are included, which are excluded, and what significant absences are there?

Therefore, the notion of 'voicing' has been analyzed in terms of speakers' performance of different social roles and voices during their online interaction following Silverstein (2004). Focus was on the use of shifters and various lexical terms to index voicing and create specific discursive positionings that achieve different interactional goals. Shifting and distancing are two main linguistic features that have been investigated in this study.

In addition, Fairclough's (2003) two factors were used to analyze the occurrences of both direct and indirect reported speech found in the data corpus. The first examines the relationship between the original quote and the quoted speech while the second investigates the link between the quoted text and the text in which it is embedded. Fairclough (2003, p.49) mentioned four ways of reporting including direct reporting, indirect reporting, free indirect reporting, and narrative report of speech act reporting. This study involved two types of reported speech. First the direct reporting, which is the actual words used in quotation marks, and the second type is the indirect reporting, which refers to a summary of what was said or written.

Excerpts of data texts are identified in 'Italic' font with 'CAPITAL' font for the word that has certain grammatical features (e.g., voicing \& shifting). In addition, 'underlining' feature is used to direct attention to the main idea in the text for more clarification. These excerpts include English translation for the Arabic words in the data corpus on Twitter. Translated Arabic words into English were often directly provided. Quotation marks were used to give direct examples 
of the occurrence of different lexical terms in the data. Within some excerpts, explanation also followed in parentheses for ambiguous expressions.

\section{FINDINGS AND DisCUSSION}

\section{A. Thematic Analysis}

The study showed discursive indexing of linguistic purism ideology by Arabic speakers in online interaction. Data demonstrated interdiscursive nature of discourse, and how it is affected by different ideological practices. Three key dimensions, namely Nationalism, Modernity and Humanity have been recognized from the data corpus as the major themes for understanding ideological perceptions of speakers in the research context. These themes are arranged subsequently into various subcategories (sub-themes) as seen in Table 1 below.

TABLE 1

THE OCCURRENCES OF DIFFERENT THEMES AND SUB-THEMES IN THE ONLINE DATA
\begin{tabular}{|c|c|c|c|}
\hline Ranking & Ideological dimension & $\begin{array}{c}\text { Occurrences } \\
\text { No. }\end{array}$ & $\begin{array}{c}\text { Occurrences } \\
\text { Prec. } \%\end{array}$ \\
\hline A & Nationalism \\
\hline 1 & Arabic identity & 20 & 19 \\
\hline 2 & Islamic identity & 14 & 13.5 \\
\hline 3 & Arabization & 7 & $\mathbf{3 9 . 5}$ \\
\hline & Total & $\mathbf{4 1}$ & 20 \\
\hline B & Modernity & 12.5 \\
\hline 1 & Communication & 21 & $\mathbf{3 2 . 5}$ \\
\hline 2 & Civilization & $\mathbf{3 4}$ & 13.5 \\
\hline & Total & 16 & 12.5 \\
\hline C & Personality & 13 & $\mathbf{2 8}$ \\
\hline 1 & Normality & $\mathbf{2 9}$ & $\mathbf{1 0 0}$ \\
\hline 2 & Total & $\mathbf{1 0 4}$ & \\
\hline & Grand total & Hunity & \\
\hline &
\end{tabular}

Nvivo software was used to classify speakers' linguistic ideologies regarding the speakers' perspectives about their language and language use. Recurrent ideological themes are discussed and then followed by the analysis of discursive ideology construction in the discourse. Thematic analysis was useful for the study purpose due to its flexibility which allows researchers to examine different experiential concerns of speakers regarding their linguistic behaviors. It also helps to investigate several personal and social factors affecting speakers' ideology and practices. According to Clarke and Braun (2017, p.297), "TA (Thematic Analysis) can be used to identify patterns within and across data in relation to participants' lived experience, views and perspectives, and behavior and practices; 'experiential' research which seeks to understand what participants' think, feel, and do". The ideological sub-themes included under the three main themes under discussion, were ranked from the most frequent into the least in each thematic section as seen in table 1 above. Further discussion of the three main dimensions and their subsequent related concepts is included in next sections.

\section{Nationalism}

One of the core themes that have been identified in the study corpus was nationalism. It was embedded in the discourse through three main subthemes including Arabic nationalism, Islamic nationalism, and Arabization. Nationalism could be recognized from the recurrent utterances about Arabic (19\%) and Islamic identities (13.5\%) within the texts (see Figs. 1 \&2). It also appeared in speaking about the ideology of Arabization (7\%), and calls for working on adapting, and localizing English words into Arabic setting. In this discourse, nationalism ideology includes indications to certain values, and ethics related to Arabic speakers' use of their language. In this section, thematic analysis for these themes is provided with sufficient discussion for the data.
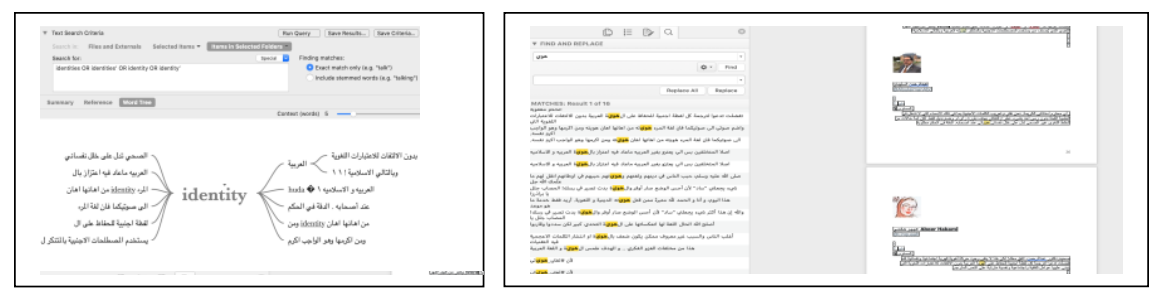

Figure 1. The occurrences of the word identity in the data corpus, Nvivo 12 (left) and MS Word (right) 


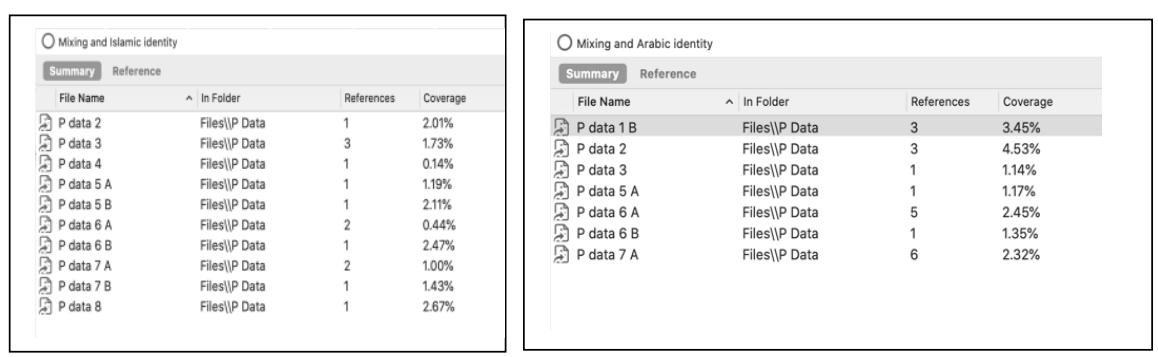

Figure 2. The frequency of the reference to both Arabic \& Islamic identity in the data corpus, Nvivo 12

One salient sub-theme that has been recognized in the data corpus was Arabic nationalism. Arabic is recognized as a core value of Arabs as an ethnic group. Arabic is considered among Arabs as a shared symbol and a marker of a group identity that must be reserved to save their ethnic identity (Suleiman, 2003,1994; Bitar,2011). Collected data proved that the national status of Arabic among its speakers affected their attitude toward languages, and different linguistic practices such as mixing languages. According to comments provided by the interactants, purism, which involves using only Arabic, was regarded as one feature of being Arabic and maintaining Arabic identity (excerpts 1 and 2).

Excerpt 1

And I join my own voice to your voices, the language of a person is his identity, then if he is insulting it he is insulting himself, and whoever valued it, (and that is what WE must do), valued himself

Excerpt 2

And I speak Arabic because MY language is MY identity

Moreover, some comments even go beyond to reflect stronger rejection of mixing by labelling people who switch as unhealthy people and who may be suffering from several psychological and cultural deficiencies (excerpt 3).

Excerpt 3

Do not say workshop but say: 'dawrah' (Arabic word for workshop), because using a foreign word in Arabic, or Arabic in a foreign sentence without a reason is not understandable and may be caused by a psychological deficiency the speaker suffers from.

Further extreme perspective against language mixing was also reflected in speakers' comments about using English. It was regarded as a 'murder' in which Arabic identity is described as the victim (excerpt 4). Others see mixing English with Arabic a kind of intellectual invasion (excerpt 5). Invasion's remnants are used metaphorically in this comment to indicate negative impact of western culture on Islamic identity and culture as expressed in Arabic world. This notion was asserted by other speakers who indicated the necessity to fight for heritage and origin as seen in excerpt 6 .

Excerpt 4

Oh, thanks God, I repudiated THAT who killed his religious and linguistic identity

Excerpt 5

This is one of the intellectual invasion's remnants, and the target is eliminating Arabic identity and language

Excerpt 6

Oh God mercy, I do not know how WE feel when WE speak English or mix, is that a damn or media trick, why WE are not proud of OUR language and the real cultural life, with media do not help US to fight for OUR heritage and origin, it is so awful, and I am so regretful because I am trapped in it

However, complex relationship between Arabic language and ethnicity in the Arabic speaking world was discussed by many researchers such as Hatoss (2013), Myers-Scotton (2005) and Suleiman (2003). Myers-Scotton, (2005, P.113) explains it saying:

But certainly not all speakers of one language are in the same nation state. The Middle East presents a different picture regarding language. Arabic is the classic vehicle in which Islam, a major ingredient in Arab nationalism, is expressed.

Hence, Arabic is often regarded as a core value for ethnicity among Arabic speakers with Muslim affiliation, but it is not usually the case with others from different religious and cultural backgrounds including some minorities in Arabic countries such as Sudanese in the South Sudan and Maronite Christian in Lebanon (Hatoss, 2013; Myers-Scotton, 2005).

However, the marked nature of language in defining identity is dynamic as it is greatly affected by many sociological, sociolinguistic, psychological, and psycholinguistic factors that interact in a complicated way, to define the most salient features identifying a group's identity, (see e.g., Hamers \& Blanc, 2000; Hatoss, 2013).

Data corpus showed strong ideological attitudes and practices toward using Arabic as the language of Islamic religion. It is described in the speakers' comments as "the language of Islam, the language of Quran, the language of worship, the language of revelation from heaven, and the language of the last prophet". Speakers' attitude to Arabic, and English indicated the ideology of Islamic nationalism. The comment below (excerpt 7) showed this strong ideology towards mixing Arabic and English which is clearly affected by the speakers' religious ideology of Arabic language:

Excerpt 7

WE must glorify OUR language and feel proud about it, as it is the language of the last revelation from the heaven and the language of the last prophet 


\section{Excerpt 8}

A: Using foreign language to show off is not modernity anymore except for THOSE who recently became modern, confident person knows more than one language but feels proud of HIS OWN language whatever this language is, especially if it is a beautiful language like the language of the Quran

$B$ : Yes, you are right all languages are poor compared to the language of the Quran

\section{Excerpt 9}

Yes, only Arabic language deserves respect because it is the language of the holy Quran and it is the one that refines behaviors and make them perfect, but the mixed and futile languages have nothing good

Moreover, the ideology of purism was asserted in the data corpus through reported speech (direct quotation) from the holy Quran (excerpt 10), and the speech of the prophet Muhammad (excerpt 30).

Excerpt 10

Mr Suliman, the psychological problem is in OUR minds, WE are mentally deficient, and this resulted from the French colonization, and the schizophrenia between present and future, as for the past, God says in His holy Quran: "Indeed, We have sent it down as an Arabic Qur'ān that you might understand." Ask THEM by God why Allah revealed this verse in Yosef surah (Joseph chapter in the holy book)

Religious ideology, expressed above, is found in various contexts among Muslims from different cultural backgrounds and within different interactional contexts (Suliman, 2003). Using "pure" Arabic and rejecting switching could be noticed from their discourse during different formal and informal interaction. Arabic, and standard Arabic in particular, has its prestigious status from the early period of Islam for its various religious, cultural, and educational functions (Suliman, 2003; Palmer, 2007; Versteegh, 2014). As mentioned earlier in this paper, diglossic condition of Arabic has a considerable role across different interactional contexts in Arabic world (see Palmer, 2007; Ferguson, 2000). Standard Arabic, which is the language of the holy book of Muslims is known as a form of high variety and thus it is typically used for formal and educational purposes. Colloquial dialects, on the other hand, are defined as low varieties of Arabic that are usually spoken during daily life conversations. The data supports similar situations that reflected diglossia of Arabic where foreign languages are defined as linguistic codes used within limited contexts for specific academic, and communicative purposes. It is also in line with several studies that showed a sort of conflict in the usage of different languages in Arabic contexts especially in academic environments that involve mixing standard Arabic with its various dialects, as well as with French and English (see e.g., Al-Asal \& Smadi, 2012; Mizher, \& AlAbed Al-Haq, 2014; Chakrani, 2011).

Dual Arabic-Islamic nationalism could be noticed from the data. Arabic was asserted as the language for both Islamic and Arabic communities. Several comments assert social, and religious values of Arabic particularly for people from Arabic- Islamic background (excerpt 11):

Excerpt 11

Only dummy people, THOSE who feel proud about languages other than Arabic, currently no one at all feels proud of Arabic and Islamic identity, there are only cheers and flashiness "Islam and language" and there is no reality

Comments in this section assert the ideology of Arabic purism and define Arabic as superior language over other due to its religious and social status specifically in Muslim-Arabic society.

Among the interesting themes that emerged in the dataset was the call for Arabization as an action should be taken to adapt English terms into the Arabic corpus. The reason behind this call was to avoid using English words within Arabic speaking contexts. The Arabization of any foreign name means that Arabs pronounce and spell it according to their grammar, orthography, and tongue (Al-Zubaidi, 1994 cited in Al-Shbiel, 2017).

The data at hand, included several comments of speakers who claim the notion of Arabization. In a post about using the English word "workshop" (see excerpt 3 above), many replies asserted the idea of the urgent need to Arabize foreign words that are commonly used by Arabic speakers in Arabic discourse (excerpt 12).

\section{Excerpt 12}

Respectful opinion my great sister, WE suggest Arabize foreign words including nouns that are not pure scientific without blaming anyone. But there are cases of linguistic mixing that are unhealthy and reflect psychological trouble and deficient identity of SOME PEOPLE, WE must be specific

What is worth mentioning in this context, is the use of several concepts that are related directly to purism and cultural identity. These concepts strongly reflect ideological concerns regarding Arabic discourse. Arabization is regarded as an action that must be taken to reveal several ethical and cultural values. "Respect, honor, pride, victory, bravery" were among the frequent words used to assert purism theory and claim strong rejection of any bilingual discourse that include mixed Arabic-English words. On the other hand, several terms were used to describe mixing negatively including "shame, insult, deficiency, stupidity, ignorance".

Hence, serious calls for Arabization, and its crucial role to develop contemporary Arabic language were recognized in the data. This finding is in line with several views and demands found in literature regarding the efforts that must be done by the Academy of the Arabic language in developing the Arabic language to cope with modernization, and scientific development (Al-Shbiel, 2017; Kharyoush, 2003; Mizher \& Al-Abed Al-Haq, 2014).

\section{Modernity}


The second main central theme that was recognized from the study corpus is modernity. Two critical sub-themes were included in this dimension namely civilization and communication. Several comments with considerable frequency $(32.5 \%)$ referred to the direct relationship between language use and social, technical, scientific, educational, and economic aspects of life. Modernity and mixing were recognized as two central interrelated ideologies in the discourse of purism. However, these comments reflected both positive and negative perspectives about mixing English words in Arabic speaking discourse.

Speakers strongly expressed their negative attitudes toward using English in Arabic contexts to show themselves as civilized people. Strong language was used to describe people who mixed their languages as "inexperienced" and "recently educated" and "(later) civilized people". "(Recent) modern" was also the expression that has been mentioned to describe people who mix English with Arabic words in their speech as people who have just known civilization (e.g., excerpts $13 \& 14)$ :

Excerpt 13

It is all right; speak whatever language you want but speak it in your study field or workplace as there is no need to show off yourself here and there because showing off with foreign language is not modernity or education anymore except for (recent) modern people

Excerpt 14

It is sad but funny thing and there are many reasons for that, SOME PEOPLE think that with this practice THEY are being modern and civilized people but, in my view, with respect, THEY are dummy. But some need it for university and study purposes, but the worst thing is when THEY ask you: 'what it means in Arabic?'.

However, other comments that assert mixing as a sign of modernity were in favor of using English terms especially nowadays in this globalized and growing interdependent world where people may need to express themselves as modern and educated through using more common international words in their speech such as inserting some English technical terms (excerpts $15 \& 16)$ :

Excerpt 15

Nowadays, most Arabic words are not found in the dictionary anymore, and if you use them, you will be so old, so learn English but do not use it more than Arabic

Excerpt 16

Unfortunately, anyone writes in Arabic, speaks Arabic, especially in private companies, is recognized as ignorant and they laugh at him. They ask YOU to use English and they are all Saudi

Using English, whether through inserting some English words or producing full English utterances, was a necessity for both inter- and intracultural communication. English globally plays a role of a lingua franca when people from different linguistic, cultural, and educational backgrounds come to communicate. Among the interesting comments that explain the role of mixing to enhance interaction are the excerpts 17,18, and 19 below in which inserting 'foreign' terms is considered understandable and justified practice.

Excerpt 17

Sometimes WE need some foreign words for more clarification of the meaning of an Arabic word and in other times some foreign words are closer to the mind than Arabic ones, that's it

\section{Excerpt 18}

Mixing is normal, and it is called code switching and it has an important role in improving communication

Excerpt 19

English is everywhere and pervades everything, I do not know why, maybe it is the media, yes, the reason is the media, movies, social media, and so on

Thus, mixing was regarded as normal or usual feature of communication to have a good opportunity in modern life and to keep pace with a great revolution of technology in modern societies.

\section{Humanity}

The third principal theme in the data corpus is humanity. Speech about humanity was interesting as speakers attempted to explain and justified the linguistic behaviors of people who mixed their languages specifically English and Arabic. Two main sub-themes related to the idea of humanity were identified including personality and normality with $15.5 \%$ and $12.5 \%$ frequency respectively. However, both positive and negative attitudes were recognized from the speakers' comments.

Mixing was described as a normal behavior for 'bilingual' speakers as they have two linguistic codes, and they may employ both during their interactions in different spaces. Education and communication through various communicative situations encourage people to practice mixing. Hence, this linguistic behavior normally appears during their daily contact (excerpts 18 'above' \& 20).

Excerpt 20

It (mixing) is a normal behavior, I am not supporting it, but it is normal and not a psychological deficient especially for people who have Arabic as a mother tongue, and they have a foreign language for communication and education 
More explanation was provided by other speakers to assert mixing as "very normal behavior" for the common and widespread usage of certain English words that are known, and usually used by people despite the existence of their Arabic equivalents (excerpt 21).

\section{Excerpt 21}

You say words like 'bank' and 'counter', and these words have equivalents in Arabic, but linguistically these words were assimilated into Arabic. they are common 'in mouths', so it is a very natural linguistic behavior

Hence, the spread of English was mentioned as one focal reason of mixing and inserting English words into Arabic contexts. The words like "common, prevalent and widespread" were frequently used by speakers when talking about using English words by Arabic speakers in different contexts (see Fig. 3):

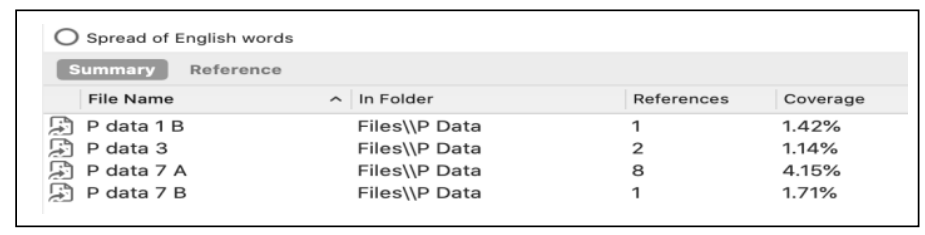

Figure 3. The frequency of the occurrence of the notion of the spread of English across the world in the data corpus, Nvivo 12

Personality was another theme which was noted from speakers' comments about language use. The effect of different personal traits on speakers' linguistic behaviors was mentioned frequently in the data. Examples of interesting ideas reflected by several speakers were mixing for being "arrogant," and "have a desire to show off" linguistic ability or modernity, as early mentioned. Another related, and exciting description that was attached to people who mix English with Arabic words was "fashionable people" who try to imitate others to seem stylish. Several characteristics that reflect strong negative attitudes toward mixing were used to describe people who speak English within Arabic discourse. Certain negative features were attached to them such as "less or not confident about themselves, ignorant, stupid, and disgusting”.

Nevertheless, some positive words were also used to describe people who mix Arabic and English in a certain context. They were described as "nice, funny, and beautiful" people. However, only (21\%) of comments about people who mix English words within Arabic discourse were identified as positive. Speakers expressed their acceptance and provided justification as a normal and expected behavior in current multilingual environments.

\section{B. Textual Analysis}

The data corpus involves different positions and roles of speakers on Twitter regarding using Arabic. There are multiple personas manifested by these speakers throughout the data which reflect dynamism in discourse and assert creative indexical moments (Reyes-Rodr' 1guez, 2008). In these moments, speakers were claiming distinctive ideological perspectives, and evoking different interactional identities. Reporting speech, voicing, shifting, and distancing are the linguistic features that were found in the data corpus, and are discussed in this section.

\section{Reporting Speech}

Several occurrences of both direct, and indirect reported speech were found in the data corpus. Reporting speech was used to reflect different perspectives regarding using diverse linguistic codes available to the speakers (Arabic and English) in a single Arabic discourse. Fairclough's (2003) two factors in analyzing reported speech were applied to analyze and explain this linguistic feature. The first examines the relationship between the original quote and the quoted speech while the second, investigates the link between the quoted text, and the text in which it is embedded.

In several replies on different posts that involved purism ideology, direct quotations from Islamic religious books were identified. They include direct quotation of verses from the Quran (see excerpt 10 above), and from Prophet Mohammad speech (excerpt 22).

\section{Excerpt 22}

Now most English words became dominant for most speech of people, the reason is not known may be for weakness in identity feeling and this could be included in the Prophet speech when he said: "You will follow the wrong ways, of your predecessors so completely and literally that if they should go into the hole of a mastigure, you too, will go there.".

These excerpts demonstrated a clear refusal of using English words within Arabic speaking contexts. They were replies on a post that requests Arab speakers to avoid using the English word (workshop or course) instead of its Arabic equivalent "dawrah". Strong expressions were used to assert the idea of speakers' tendency for assimilation through acting and speaking like western people (English and French native speakers in particular as in the two examples above) In excerpt 10, after asserting the idea of abnormality of mixing languages, the speaker elaborated his speech by direct reporting of verses from the Quran for demonstrating the high value of Arabic being the language of the holy Quran.

Similarly, excerpt 22 showed the strong ideology against dominance of foreign terms in Arabic speaking context. After attempts to discover the reasons behind switching, direct quotation of Prophet Muhammad speech was added. The hadith of the Prophet, cited above, is usually used to draw Muslims' attention to avoid following other cultures. Such 
religious quotations are used to assert mixing as non-favorable behavior that reflects the desire of identity assimilation or shift.

In addition, the data involved several Islamic expressions that are quoted from the Quran, and Prophet Muhammad discourse such as "(We belong to Allah and to Him we shall return), (There is no power and no strength except with Allah), and (God bless you). It is a common feature of Islamic discourse to serve various pragmatic and social functions (Susanto, 2006; Almansour, 2010). Thus, these quotations are usually borrowed, and used by people in both Arabic and Islamic discourse.

Moreover, various quotations from Arabic literary texts were identified in the data. They include verses from famous Arabic poems that reflect the beauty, and the high value given to Arabic over other languages (excerpts 23 \&24):

\section{Excerpt 23}

As Hafiz Ibrahim said: I am the sea in my depths, pearls are concealed, so can they ask the diver about my shells!

Excerpt 24

My language, and I am proud I fell in love with it, it is the beauty, and its merit is clarity It is Arabic, there is no doubt that the Quran is prominent in its rhetoric.

In this discourse, both direct and indirect reported speech were used to approve or disapprove switching of speech. These examples were mostly given to assert that mixing is wide-spread, and inevitable linguistic behavior during communication in the modern world; as explained by the speakers in excerpts 25 and 26 .

Excerpt 25

I sat there to explain and theorize about the importance Arabizing science, and I provided some proofs and evidence and I said while I am Arab and "the patient" (English word inserted) is Arab why we teach them in English, and this was very disappointing as it was contradicting self in such an honorable case

Excerpt 26

It is widely spread in Egypt when you come to download an application, they, for example say do you want ("tset up= to set up") the program ( $t=$ is an Arabic inflectional morpheme means to)

These quotations assert the idea of Arabic purism whether it was directly meant through the verses that explain the superiority of Arabic over other languages for being the language of the Quran or indirectly as in several comments which reflect the notion of being independent and proud of the identity and avoiding using others' (often Western people) norms of behaving including their languages.

Using religious expressions that reflect unsatisfaction with this linguistic behavior also indicates the purism ideology of people in this context. These religious expressions interweave within the narrative about the context of being in contact with Arabic background speakers where Arabic could be used as the only means of communication with no need for any other linguistic code.

\section{Voicing, Shifting, and Distancing}

Voicing, shifting, and distancing are other linguistic features that have been recognized from the data corpus. The data involved invoking of different social roles and voices into distinctive online interactional exchanges. There was use of shifters to index voicing in the data context. Several lexical terms were also used to create specific discursive positionings and achieve different interactional goals.

Using pronouns was one prominent linguistic feature that serves several functions in the discourse. Pronouns were employed to index distance and create otherness (Silverstein, 2004). Using plural personal voice "WE” (e.g., excerpts 1,6 \&7) served the function of collective identification as indicated by Brewer and Gardner (1996). Pronouns also imply the meaning of speaking from the position of the wider Arabic community by relating their shared concern (excerpt 27).

\section{Excerpt 27}

Exactly, WE must be proud about OUR language under any circumstances, foreign utterances must never be used and inserted into OUR Arabic language, and WE say it is a part of OUR speech. unfortunately, I see interviews, you do not know, and you may feel shocked of PEOPLE and how THEY are blundering in speech from Arabic into English

Likewise plural personal voice "US" (excerpt 6) as well as the possessive, both singular and plural, pronouns " $M Y \&$ OUR" (excerpts $17 \& 34$ ) were also used to reflect Arabic community voice and show distance from others. Moreover, by using these pronouns speakers may invoke the Islamic society voice. This claim could be recognized through direct reporting of different religious texts and expressions as discussed above.

In excerpt 34 above, the speaker also changed voice between the narrator and the interlocuter to show solidarity (Reyes-Rodr'iguez, 2008). While the speakers include certain groups of people (speakers of pure Arabic) and recommend them to keep speaking pure Arabic utterances, they exclude others who mix languages. Thus, the third person plural, both subjective and objective, "THEY \& THEM" (e.g., excerpts 10 \& 14 above) as well as the demonstrative pronouns "THAT \& THOSE" (e.g., excerpts $4 \& 8$ above) were used, to mark distance from the other people who insert English words into their Arabic speech.

Furthermore, the data include using of some vocative items that served different interactional functions. Two main functions that have been identified from the data were directing interlocuter attention, and asserting solidarity, for example, "My dear brother, my dear sister, my dear daughter, my son" and others showing respect (e.g., "my teacher, 
our leader, boss"). Additionally, formal address such as “Mr., sir, and Dr." were used for similar purposes. Speakers in these utterances employed such vocative voices to express distinct levels of power including parents' voices, brothers, children, teachers, and students. This asserts creative use of different linguistic features to index ideology in interaction.

Moreover, there was noticeable use of specific lexical items to index purism ideology of speakers. Several lexical items were used to show distance and reposition of self and others. "People, some, someone, group, and elite" are among words frequently used to describe speakers who switch their Arabic speech into English.

Purism ideology could also be recognized from the frequent referencing to the three different periods of time 'past, present, and future' (see excerpt 10 above) and especially words connecting to the 'past' like "history, heritage, parents, grands, past generation". These words reflect both spatial and temporal links to different contexts and showed speakers use of different contextual markers. Calling for reposition to the past invokes the Islamic society voice of power in the past in which Arabic is recognized as main feature of Islamic worships (Suliman, 2003; Versteegh, 2014). This may explain the reason for holding Arabic language purism ideology. Arabic was claimed to be the language of past, present, and future and thus it must survive and not to be tied to specific context or time as it is related to Islam to accomplish several religious practices such as prayers, and recitation of the Quran.

\section{CONCLUSION}

This study aimed to explore the sociolinguistic aspects of language ideology embedded in online interaction of Arabic speakers. The ideology of language purism, and more specifically Arabic purism was the problem under study. CDA approach was used as a theoretical framework to analyze the study data. Through this approach, both textual and sociological perspectives of the Arabic purism ideology were investigated.

The study asserted discursive indexing of linguistic purism ideology among Arabic speakers on Twitter. Nationalism was indicated as one of the most powerful factors affecting people's attitudes to their linguistic practices. The data asserted the considerable influence of people's cultural ideologies related to Islamic and Arabic identities on their language use, and attitude. Calls for Arabization as an important action prevailed purists' speech to save Arabic and Islamic identity.

Besides, modernity and switching were recognized as central interrelated ideologies in the discourse of Arabic purism. Despite the prevalence of negative attitudes toward mixing, it was described as critical behavior that fulfills various communicative, integrative, and affective functions in modern life. It was considered necessary to keep pace with a great revolution of technology in current modern and multilingual societies. Speakers' comments about mixing as normal and personal behavior asserted the significant role those ideologies play in their attitudes towards language purism. There were noticeable agreement and acceptance for inserting English in Arabic discourse. Through the intertextual analysis of the discourse, several linguistic features of texts were also recognized including reporting speech, voicing, and shifting. These features served various pragmatic and social functions in this interactional context.

\section{REFERENCES}

[1] Ag, A., \& Jørgensen, J. (2013). Ideologies, norms, and practices in youth poly- languaging. International Journal of Bilingualism, 17(4), 525-539.

[2] Al-Asal, M., \& Smadi, O. (2012). Arabicization and Arabic Expanding Techniques Used in Science Lectures in Two Arab Universities. Asian Perspectives in the Arts and Humanities, 2(1), 15-38.

[3] Al-Shbiel, A. (2017). Arabization and Its Effect on the Arabic Language. Journal of Language Teaching and Research, 8 (3), 469-475.

[4] Bitar, S. (2011). Language, Identity, and Arab Nationalism: Case Study of Palestine. Journal of Middle Eastern and Islamic Studies (in Asia), 5 (4), 48-64.

[5] Brewer, M., \& Gardner, W. (1996). Who is this" We"? Levels of collective identity and self representations. Journal of Personality and Social Psychology, 71(1), 83-93.

[6] Burridge, K. (2010). Linguistic cleanliness is next to godliness: taboo and purism. English Today, 26(2), 3-13.

[7] Chakrani, B. (2011). Covert Language Attitudes: A New Outlook on the Sociolinguistic Space of Morocco. In E. G. Bokamba et al. (Eds.), Selected Proceedings of the 40th Annual Conference on African Linguistics (pp. 168-177). Somerville, MA: Cascadilla Proceedings Project.

[8] Clarke, V., \& Braun, V. (2017). Thematic analysis. The Journal of Positive Psychology, 12 (3), 297-298.

[9] Cummins, J. (2008). BICS and CALP: Empirical and theoretical status of the distinction. In N. Hornberger et al. (Eds.), Encyclopedia of language and education (pp. 487-499). New York: Springer.

[10] Fairclough, N. (2001). Language and power (2nd ed.). London: Longman.

[11] Fairclough, N. (2003). Analyzing discourse: Textual analysis for social research. London: Routledge.

[12] Fairclough, N. (2012). Critical discourse analysis. International Advances in Engineering and Technology, 7, 452-487.

[13] Feng, X., \& Behar-Horenstein, L. (2019). Maximizing NVivo Utilities to Analyze Open-Ended Responses. The Qualitative Report, 24(3), 563-571.

[14] Ferguson, G. (2000). Diglossia. In W. Li (Ed.), The bilingual reader (pp. 58-73). London and New York: Routledge.

[15] Garcia, O. (2009). Bilingual education in the 21st century: A global perspective. US: Wiley-Blackwell.

[16] Garcia, O., \& Sylvan, C. (2011). Pedagogies and practices in multilingual classrooms: Singularities in pluralities. The Modern Language Journal, 95(3), 385-400. 
[17] González, N. (2003). Language ideologies. Paper Presented at Second National Conference on Heritage Languages in America, $23-25$.

[18] Hamers, J., \& Blanc, M. (2000). Bilinguality and bilingualism. Cambridge: Cambridge University Press.

[19] Hatoss, A. (2013). Displacement, language maintenance and identity: Sudanese Refugees in Australia. Amsterdam and Philadelphia: John Benjamins Publishing Company.

[20] Jørgensen, J., Karrebæk, M., Madsen, L., \& Møller, J. (2011). Polylanguaging in superdiversity. Diversities, 13(2), 23-37.

[21] Kharyosh,A. (2003). Arabization Movement in Jordan. Amman: The Ministry of Culture.

[22] Li, W. (2000). The bilingualism reader. London: Routledge.

[23] Li, W. (2011). Moment analysis and translanguaging space: Discursive construction of identities by multilingual Chinese youth in Britain. Journal of Pragmatics, 43(5), 1222-1235.

[24] Liebscher,G. \& Dailey-O'Cain, J. (2009). Language attitudes in interaction. Journal of Sociolinguistics. 13(2), $195-222$.

[25] Mizher, R., \& Al-Abed Al-Haq, F. (2014). Attitudes towards using standard Arabic among academic staff at Balqa Applied University/Center in Jordan: A sociolinguistic study. International Journal of English Linguistics, 4(1), 53-59.

[26] Myers-Scotton, C. (2005). Multiple voices: An introduction to bilingualism. USA: Blackwell Publishing.

[27] Nugaraite, I. (2017). Standard Language Ideology and Its Influence on Lithuanian Migrants. Samogitians' Attitudes towards Their Language Variety. Sustainable Multilingualism, 11(1), 14-33.

[28] Palmer, J. (2007). Arabic diglossia: Teaching only the standard variety is a disservice to students. Arizona Working Papers in SLA and Teaching, 14, 111-122.

[29] Reyes-Rodr'iguez, A. (2008). Discursive strategies in Chavez's political discourse: voicing, distancing, and shifting. Critical Discourse Studies, 5 (2), 133-152.

[30] Silverstein, M. (2004). 'Cultural' concepts and the language-culture nexus. Current Anthropology, 45, 621 - 652.

[31] Suleiman, Y. (1994). Nationalism and the Arabic language: A historical overview, In Y. Suleiman (Ed.), Arabic sociolinguistics: Issues and perspectives (pp. 3-24). Surrey: Curzon Press.

[32] Suleiman, Y. (2003). The Arabic Language and National Identity: A Study in Ideology. Edinburgh: Edinburgh University Press Ltd.

[33] van Dijk, T. A. (1998). Ideology: A multidisciplinary approach. London: Sage.

[34] Versteegh, K. (2014). The Arabic language. Edinburgh: Edinburgh University Press.

[35] Watson, J. (2007). The phonology and morphology of Arabic. Oxford: OUP.

[36] Woolard K., \& Schieffelin B. (1994). Language ideology. Annu. Rev. Anthropol. 23,55-82.

Albatool Ahmad Alhazmi is an assistant professor in English Dept. and vice dean of the college of languages and translation, Najran University. She has her masters and PhD. from UNSW, Australia. Research areas are discourse analysis, language acquisition and bilingualism. 